\title{
METHODOLOGY OF EVALUATION OF THE IMPACT OF PICKING AREA LOCATION ON THE TOTAL COSTS OF WAREHOUSE
}

\author{
Raitis Apsalons, Gennady Gromov \\ Transport and Telecommunication institute, Transport and Logistics department \\ Riga, Latvia, Lomonosova 1 \\ +37126527874,raitis.apsalons@inbox.lv,gromov@tsi.lv
}

\begin{abstract}
The picking system and the layout of the picking area are the key drivers for the evaluation of a warehouse picking cost. There are five variants for organizing the picking process of orders in a warehouse. The choice of a specific variant depends on the total cost of picking. The picking cost is evaluated within an uninterrupted picking process. It means that no stock out occurs in the time period of the picking process. The storing area and the picking area are created as two separate zones for picking quantities of the customer's orders; the principle of division of orders is observed strictly. Referring to the locations of stock keeping units (SKU), two approaches of the layout of SKU in the picking area can be estimated. The first one is the single picking location for each single SKU, where replenishment is realized in the picking process. The second one - various picking locations for each single $\mathrm{SKU}$, and the replenishment here is realized just only prior to a picking process or after it. The main benefits of the economy of the picking cost as far as these two approaches are concerned are the shortest picking route in the first case and one common replenishment option in the second case.
\end{abstract}

Keywords: Picking process, picking area, layout, picking cost, replenishment of SKU

\section{Introduction}

The picking process is the most complicated process of a warehouse. The total picking costs usually depend on a choice of the picking system and the layout of the picking area (PA) (Tompkins et al., 2010). The total picking costs could be minimised by the ways of organising picking: single order picking (Andriansyah et al., 2009), picking of several orders at once, or orders' batch picking (Koster, 1999), (Won and Olafson, 2005). Some warehouses develop the organisation of picking called technology dashboard (Solovyova, 2008). In this case each item is stored separately on the pallet. The picking process of orders for the incoming orders is usually carried out in full pallets (FPLL) and if the demanded picking quantities are less than a single full pallet then the picking process is executed in handling units (HU) and customer units (CU) (Frazelle, 2002).

For planning logistical processes in a warehouse different approaches and methods could be approbated for the purpose of cost management (Lukinskiy et al., 2016). To solve problems of warehouses and terminals, the queuing theory can be applied (Lukinskiy et al., 2016). Popular solutions for products layout in PA and storage area (SA) are made by using linear programming (Ballou, 1999). Proceeding from the fact that stock keeping units (SKU) allocation is affected by seasonal factors, dynamic slotting could be appropriated, considering the recalculations of parameters of collecting goods from SA and PA (Yuryev, 2008).

There are several variants of how to organise the picking process of orders in a warehouse, proposed by the authors:

1) Variant 1: Picking from a single area - there is only SA in the warehouse, for reaching the highest levels of racks in the picking process both pallet forklifts are used for extracting FPLL, and also high level order pickers (HLOP) for extracting HU and CU.

2) Variant 2: Picking from two separate zones, additionally using the principle of dividing of orders (PDO), FPLL are collected from SA, but HU and CU from PA (Apsalons, 2012).

3) Variant 3: Picking from two separate zones, but PA is located in SA, by using additionally the PDO, FPLL are collected from SA (the second and higher levels of pallet racks are used), but $\mathrm{HU}$ and CU from PA (the first two levels of pallet racks are used).

4) Variant 4: Picking from three separate zones, additionally using the PDO, FPLL are collected from SA, HU - from the first PA (PA1) and CU are picked from the second PA (PA2).

5) Variant 5: Automated picking systems, for example the AS/RS - Automated Storage and Retrieval System, expressed as the goods to man picking system (G2M). 
The authors of this paper analyse and compare the man-to-goods (M2G) picking system. The authors have considered the first 4 variants of picking processes. The M2G picking system means that the picker - a warehouse worker is collecting different SKU according to picking list given by a warehouse clerk. Usually, printed picking lists are used or picking lists are available as information in the picking scanners. From the practical point of view, the M2G picking system generally consists of the following parts:

Step 1: The picker activates scanner by entering his password, pressing the button „begin task” for picking;

Step 2: The picker receives the picking list in his scanner according to a fixed list of priorities;

Step 3: The picker begins picking following the given picking route;

Step 4: When the picking starts, picker goes up to the given picking place and scans the required barcode of the product;

Step 5: The picker goes to the next given picking place by carrying on step 4 up to the point when the picking list is not completed, then the button ,finished” is pressed;

Step 6: If after picking there are separate transport packages left, then the warehouse of the logistics centre needs additional packing process;

Step 7: Then the picker moves the complete (picked) order to the given departure zone according to the assignment of the warehouse clerk or scanner.

The main purpose of the paper is to evaluate the impact of the layout of PA on the total picking cost of the warehouse referring to the $\mathrm{M} 2 \mathrm{G}$ picking system. Consequently, the definition of the scientific problem is to provide the methodology of evaluation of picking cost within an uninterrupted picking process.

The object of the research focuses on storing and picking areas. The subject of the research concerns the interconnection of total handling costs of a replenishment process and those of a picking process.

The picking cost is an optimising criterion for the evaluation of variants for organizing the picking process of orders. Additionally, there are two approaches considered for the layout of SKU in PA:

1) Single picking location for each single item - the replenishment is carried out in the picking process.

2) Various picking locations for each single item - the replenishment is carried out only just before a picking process or after it.

\section{Description of the Task for Picking Customers' Orders}

To presume that a warehouse receives a definite number of orders a day in the Warehouse Management System (WMS): $\mathrm{O}_{\mathrm{N}}$ for the delivery next day, each order: $\mathrm{O}_{1} ; \mathrm{O}_{2} ; \ldots ; \mathrm{O}_{\mathrm{N}}$; where $\mathrm{N}-$ is the number of orders per day. To assume it to be a single order: $\mathrm{O}_{\mathrm{i}}$. The process of receiving orders lasts until a definite time moment TM (for example, TM=12 AM). After that the process of receiving orders is closed by a warehouse clerk or a client service specialist. Thus, orders, coming into the system after TM, will remain for the delivery the next day after tomorrow. The total number of orders $(\mathrm{O})$ is equal to the sum of all single orders:

$\mathrm{O}=\sum_{\mathrm{i}=1}^{\mathrm{N}} \mathrm{O}_{\mathrm{i}}$.

Each order is a function of definite number of order lines $\mathrm{OL}_{\mathrm{ij}}(\mathrm{j}-\mathrm{a}$ specific order line of a specific order $\mathrm{i})$, which corresponds to the ordered number of SKU:

a) for order 1: $\mathrm{O}_{1}=\mathrm{f}\left(\mathrm{OL}_{11} \quad \mathrm{OL}_{12} \quad \ldots . . \quad \mathrm{OL}_{1 \mathrm{M}}\right)$;

b) for order 2: $\mathrm{O}_{2}=\mathrm{f}\left(\begin{array}{llll}\mathrm{OL}_{21} & \mathrm{OL}_{22} & \cdots . & \mathrm{OL}_{2 \mathrm{M}}\end{array}\right)$;

c) for the last order $\mathrm{N}: \mathrm{O}_{\mathrm{N}}=\mathrm{f}\left(\mathrm{OL}_{\mathrm{N} 1} \quad \mathrm{OL}_{\mathrm{N} 2} \quad \ldots \ldots, \quad \mathrm{OL}_{\mathrm{NM}}\right)$.

$\mathrm{M}$ - last order line of a single order.

Then formula (1) for all orders within a day can be expressed as follows:

$\mathrm{O}=\mathrm{f}\left(\sum_{\mathrm{i}=1}^{\mathrm{N}} \mathrm{OL}_{\mathrm{ij}}\right)$.

Since each order line is a definite quantity of definite SKU to be picked, then:

$\mathrm{O}=\mathrm{f}\left(\sum_{\mathrm{i}=1}^{\mathrm{N}} \mathrm{Q}_{\mathrm{ik}}\right)$,

where: $Q_{i k}-$ demanded picking quantities of each SKU for each order;

$\mathrm{k}-$ the number of all SKU. 
The PDO states that those quantities $Q_{i k}$ for each SKU are divided into two parts:

1) For picking full pallets from $\mathrm{SA}: Q_{i k_{-} S A}$ (expressed in customer units from SA).

2) For picking handling units and customer units $(\mathrm{HU}+\mathrm{CU})$ from PA: $Q_{i k_{-} P A}$ (expressed in customer units from PA).

Figure 1 describes the physical flow of ordered SKU. It starts from the moment when the warehouse receives a definite number of customers' orders within a day in WMS. These orders are given for picking and PDO is used. After that the picked quantities of each SKU are checked by a controller in order to verify whether the collected quantities correspond to the demanded quantities of each single order. It is done in orders quantities control area. Thereafter the checked quantities are forwarded to the loading area for deliveries.

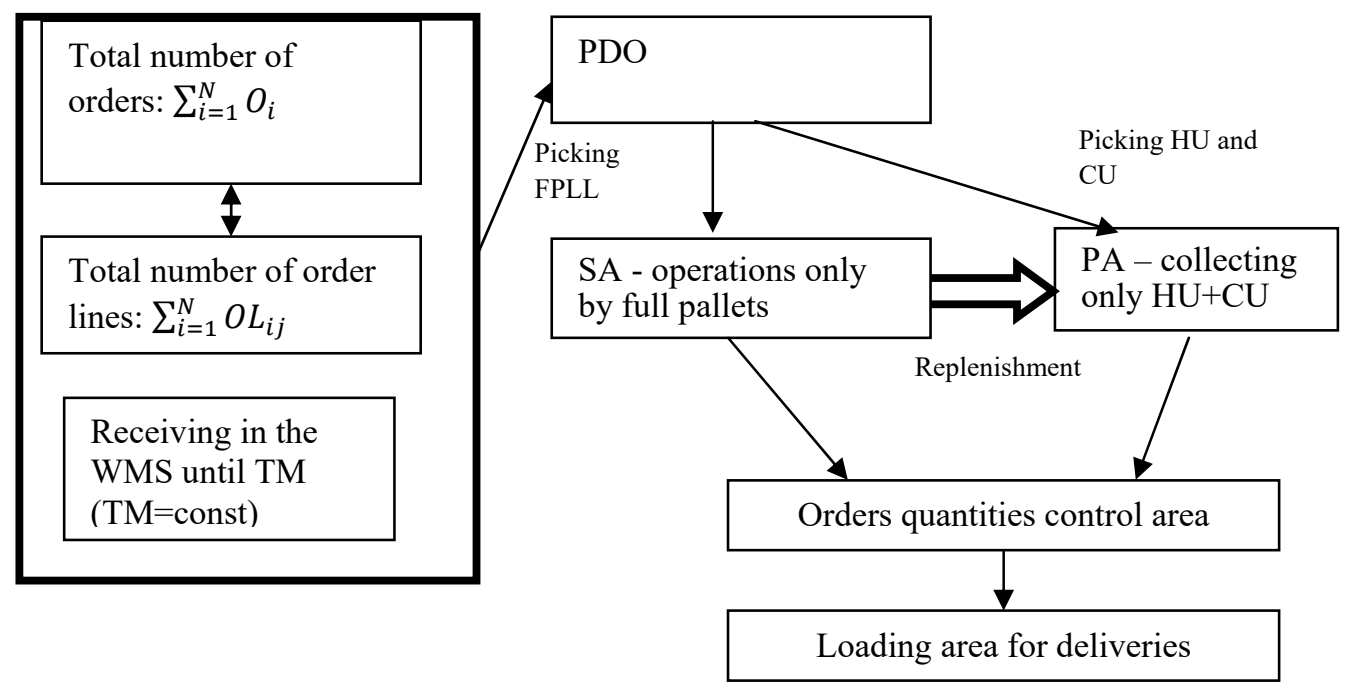

Figure 1. Scheme of description of the task for organizing order picking process in a warehouse

It means that:

$\mathrm{Q}_{\mathrm{ik}}=\mathrm{Q}_{\mathrm{ik} \_\mathrm{SA}}+\mathrm{Q}_{\mathrm{ik} \_\mathrm{PA}}$.

Then formula (3) for all orders within a day w can be expressed as follows:

$\mathrm{O}=\mathrm{f}\left(\sum_{\mathrm{i}=1}^{\mathrm{N}} \mathrm{Q}_{\mathrm{ik} \_ \text {PA }} ; \sum_{\mathrm{i}=1}^{\mathrm{N}} \mathrm{Q}_{\mathrm{ik}_{-} S A}\right)$.

As the issues the research concern the picking area and replenishment, the further analysis will be focused on the quantities of PA $\left(Q_{i k_{-} P A}\right)$, because it has been assumed that no problems exist with stock in full pallets in the SA.

The assumption is $100 \%$ stock availability for orders picked from SA and for replenishment.

\section{Optimization of Total Handling Cost and Solving the Product Layout Problem by Using Linear Programming Formulation}

\subsection{Linear programming conditions}

Further on, the analysis is made with respect to the main solution variants of the impact of the picking area layout on the total picking cost in a warehouse, which were provided by different authors.

The first solution variant is the development of a linear programming model, including inbound and outbound flows for obtaining the total material handling cost. Because of different amounts of each SKU to be handled, the problem concerns the correct layout problem of these SKU.

The general linear programming formulations of the product layout problem are described for both: SA and PA. The parameters to be involved in the linear model (Ballou, 1999) are as follows:

1) $X_{i j}$ - amount of product $j$ stored in bay $i$.

2) $C_{i j}-$ cost for handling product $j$ in bay $i$.

3) $\mathrm{M}$ - number of storage bays in both: PA and SA.

4) $\mathrm{N}$ - number of different stock SKU handled by the warehouse. 
5) L - number of storage bays in SA.

6) $\mathrm{Gj}_{\mathrm{j}}$ - amount of product $\mathrm{j}$ that can be stored in a bay.

7) $R_{j}$ - the required amount of product $j$ to be stored in the warehouse.

8) $\mathrm{Raj}$ - the minimum amount of product $\mathrm{j}$ to be stored in PA.

9) s and a-superscripts to denote sections of SA and PA.

The objective is to minimize the total materials handling cost (Ballou, 1999):

$\mathrm{Z}_{\min }=\sum_{\mathrm{i}=1}^{\mathrm{M}} \sum_{\mathrm{j}=1}^{\mathrm{N}} \mathrm{C}_{\mathrm{ij}} \mathrm{X}_{\mathrm{ij}}$

SA bay capacity constraint:

$\sum_{j=1}^{N} \frac{X_{i j}}{G_{j}^{s}} \leq 1$ for $i=1,2, \ldots \ldots, L$.

PA bay capacity constraint:

$\sum_{j=1}^{N} \frac{X_{i j}}{G_{j}^{a}} \leq 1$ or $L+1, L+2, \ldots \ldots, M$.

The minimum number of units of each SKU to be stored in PA:

$\sum_{\mathrm{i}=\mathrm{L}+1}^{\mathrm{M}} \mathrm{X}_{\mathrm{ij}} \geq \mathrm{R}_{\mathrm{j}}^{\mathrm{a}} \mathrm{r} \mathrm{j}=1,2, \ldots \ldots, \mathrm{N}$.

The total number of units SKU to be stored throughout the warehouse:

$\sum_{i=1}^{M} X_{i j} \geq R_{j}$ for $j=1,2, \ldots \ldots, N$.

Finally, a negative amount of product $\mathrm{j}$ cannot be stored:

All $\mathrm{X}_{\mathrm{ij}} \geq 0$.

However, this linear programming has some gaps from the practical point of view:

1) each product SKU has equal cost for handling product $j$ in a single bay $i$;

2) there is no division of total handling cost, for example, extracting cost from SA, picking cost from PA and, finally, replenishment cost - for moving each product SKU from SA to PA;

3) each quarter or each month the product layout of each SKU is different, and it depends on the fluctuation of inbound and outbound flows affected by seasonal factor;

4) the placement of different SKU in SA is not usually fixed - the placement of any single product is based on the principle: to put it in storage in the nearest empty pallet address so that handling cost could be minimised.

\subsection{Dynamic slotting programming conditions}

The second variant of solution might be the use of a dynamic slotting. The dynamic slotting means the recalculations of parameters of collecting goods from SA and PA. The main management task of any warehouse is to choose optimal topology of PA (Tompkins et al., 2010) for effective allocation of each SKU, for handling and controlling them. As a demand for quantities of collected SKU is not constant but varies, the main aim is to minimise total handling (picking) cost, because some SKU are expressed by larger turnover volume at the same time analysis. Additionally, it is very important to make analysis of planned order structure expressed by order lines and by quantities in full pallets, HU and CU, or other conditions (Bustillo et al., 2015). Overview of slotting strategies with an emphasis on the Cube per Order Index (COI) and affinity-based methods such as Order Oriented Slotting (OOS) and Pick Frequency/Part Affinity (PF/PA) Slotting is given by Koffler et al. (2014). The new assignment strategy for warehouses is offered by Mantel et al. (2007).

Total handling of cost depends on (Yuryev, 2008):

1) the number of replenishment in a certain time period $\left(R_{x}\right)$.

2) the quantity of replenishment of each $\operatorname{SKU}\left(Q_{i}\right)$.

3) the time interval after that replenishment has been done $\left(\mathrm{R}_{\mathrm{t}}\right.$.

The replenishment cost depends on the number of replenishment within a time period, for example, once i a day. The number of replenishment is affected by a type of each item. For example, picking from PA is carried out HU which are located on the pallet. Allocation of single SKU in SA is done by full pallets. Therefore, in the case of replenishment movement of a single item is also done by 
full pallets. Then replenishment cost is calculated as a number of travels from SA to PA, and it includes different variable cost, and personnel costs (wages) for workers involved in this process.

The specific SKU flow is expressed by its volume in $\mathrm{m}^{3}$ within a given time period:

$\mathrm{F}_{\mathrm{i}}=\mathrm{Q}_{\mathrm{i}} \cdot \mathrm{V}_{\mathrm{HUi}} / \mathrm{A}_{\mathrm{HU} \_\mathrm{CUi}}$

where: $F_{i}$ - each SKU flow, $\mathrm{m}^{3} /$ period;

$\mathrm{Q}_{\mathrm{i}}$ - quantity of SKU's, units/period;

$\mathrm{V}_{\mathrm{HUi}}$ - capacity of handling units, $\mathrm{m}^{3} / \mathrm{HU}$;

$\mathrm{A}_{\mathrm{HU} \mathrm{CUi}}$ - quantity of SKU into HU, units/HU.

The numbers of replenishment for each SKU within a time period:

$\mathrm{R}_{\mathrm{x}}=\mathrm{F}_{\mathrm{i}} / \mathrm{V}_{\mathrm{i}}$,

where: $\mathrm{V}_{\mathrm{i}}$ - each SKU capacity of PA; $\mathrm{m}^{3} / \mathrm{SKU}$.

The main task is to calculate the parameters of PA, accepting that there are no limitations referring to quantities to be stored in SA.

Parameters to be involved in this dynamic slotting programming are:

1) $\mathrm{ATC}_{\mathrm{PA}}$ - average picking cost from $\mathrm{PA}, \mathrm{EUR} / \mathrm{m}^{3}$;

2) $\mathrm{ATC}_{\mathrm{SA}}$ - average picking cost from $\mathrm{SA}, \mathrm{EUR} / \mathrm{m}^{3}$;

3) $\mathrm{ATC}_{\mathrm{R}}$ - average replenishment cost for moving quantities from $\mathrm{SA}$ to $\mathrm{PA}, \mathrm{EUR} / \mathrm{m}^{3}$;

4) $\mathrm{V}_{\mathrm{i}}$ - each SKU capacity of $\mathrm{PA}, \mathrm{m}^{3} / \mathrm{SKU}$;

5) $X_{i}$ - proportion of each SKU, which is to be extracted from PA, coefficient or $\%$, if $X_{i}=1$, then item picking place is planned in $\mathrm{PA}$, etc., $\mathrm{V}_{\mathrm{i}} \neq 0$; if $\mathrm{X}_{\mathrm{i}}=0$, then item picking place is not planned in PA, etc., $\mathrm{V}_{\mathrm{i}}=0$.

Therefore, average handling cost, considering the picking from PA and the replenishment, will be: $\mathrm{ATC}_{\mathrm{PA}}+\mathrm{ATC}_{\mathrm{SA}}$, in case if PA is planned. To assume that $\mathrm{O}_{\mathrm{i}}$ are the numbers of orders of SKU within a planned time period. The principle of dividing orders is appropriated for each order. Then minimum total handling cost is expressed (Jurjev, 2008) as follows:

$\operatorname{MIN}_{(V i ; X i)} \sum_{i=1}^{N}\left[\left(A T C_{P A} \bullet O_{i}+\frac{A T C_{R} \bullet F_{i}}{V_{i}}\right) \bullet X_{i}+A T C_{S A} \bullet O_{i} \bullet\left(1-X_{i}\right)\right]$,

where: $\mathrm{N}$ - number of SKU;

$\mathrm{F}_{\text {pll }}$ - capacity of one full pallet,

$V_{i} \leq F_{p l l}, V_{i} \leq F_{i}, V_{i} \geq 0$,

$X_{i}=\{0 ; 1\}$ (Jurjev, 2008).

There are some essential moments which are not included in the formula (14):

1) Different types of orders - extracting of any item of orders is usually carried out by full pallets, by $\mathrm{HU}$ or $\mathrm{CU}$, or combined.

2) Discreetness of storage of each item - PA is divided by pallet addresses, the length, depth and height of a single pallet are fixed.

3) Reorganizing cost of PA has to be considered.

\section{Methodology of Evaluation of Picking Cost within an Uninterrupted Picking Process Developed by the Authors}

Picking cost is evaluated within an uninterrupted picking process. It means that no stock out occurs at time period of picking process. The first issue is which picking is more effective - from one SA or from separate areas: SA and PA. In the latter case PDO and thereto replenishment process is additionally needed.

The total cost of order picking process from one single $\mathrm{SA}$ is $\mathrm{TC}_{\text {picking(SA), but, if two separate }}$ areas exist: $\mathrm{TC}_{\text {picking }(\mathrm{SA}+\mathrm{PA})}$. Usually, picking cost for two opposite choices can be expressed:

$\mathrm{TC}_{\text {picking(SA) }}>\mathrm{TC}_{\text {picking }(\mathrm{SA}+\mathrm{PA})}$.

In this case, in the expression (15), two separate areas are used in the warehouse due to lower total picking cost. If the result of expression (15) is opposite, then the picking process is carried out from one 
single SA by using pallet forklifts for extracting full pallets, and high level order pickers for collecting $\mathrm{HU}$ and $\mathrm{CU}$.

Total order picking cost from one single $\mathrm{SA}$ is:

$\mathrm{TC}_{\text {picking }(\mathrm{SA})}=\sum_{\mathrm{i}=1}^{\mathrm{N}} \mathrm{TC}_{\text {picking_PAL_i }}+\sum_{\mathrm{i}=1}^{\mathrm{N}} \mathrm{TC}_{\text {picking_SA_HU_CU_i }}$,

where: a) $\sum_{\mathrm{i}=1}^{\mathrm{N}} \mathrm{TC}_{\text {picking_PAL_i }}$ - orders' picking cost for extracting full pallets from SA;

b) $\sum_{\mathrm{i}=1}^{\mathrm{N}} \mathrm{TC}_{\text {picking_SA_HU_CU_i }}$ - orders picking cost for collecting $\mathrm{HU}$ and CU from SA;

c) $\mathrm{N}$ - the number of orders per month (or per quarter, or per year).

The total cost of orders picking process for two separate areas, should be evaluated:

$\mathrm{TC}_{\text {picking }}(\mathrm{SA}+\mathrm{PA})=$

$\sum_{\mathrm{i}=1}^{\mathrm{N}} \mathrm{TC}_{\text {picking_PAL_i }}+\sum_{\mathrm{i}=1}^{\mathrm{N}} \mathrm{TC}_{\text {picking_PA_HU_CU_i }}+\sum_{\mathrm{h}=1}^{\mathrm{H}} \mathrm{TC}_{\text {replenishment(SA_to_PA)_h }}$

where: a) $\sum_{i=1}^{\mathrm{N}} \mathrm{TC}_{\text {picking_PA_HU_CU_i }}$ - orders picking cost for collecting $\mathrm{HU}$ and CU from SA;

b) $\sum_{\mathrm{h}=1}^{\mathrm{H}} \mathrm{TC}_{\text {replenishment(SA_to_PA)_h }}$ - the cost of replenishment from SA to PA;

c) $\mathrm{H}$ - number of replenishment.

If total picking costs from one general storing area is more than picking from separate areas SA and PA, consider additionally replenishment process and the PDO has been used.

If picking in $\mathrm{HU}$ and $\mathrm{CU}$ is done from SA, then picking cost is more comparing with withdrawing stock from picking area by the equal number of orders to be picked:

$\sum_{\mathrm{i}=1}^{\mathrm{N}} \mathrm{TC}_{\text {picking_SA_HU_CU_i }}>\sum_{\mathrm{i}=1}^{\mathrm{N}} \mathrm{TC}_{\text {picking_PA_HU_CU_i}}$.

Then the total picking cost for several variants of organizing orders picking process in a warehouse can be compared. The average picking costs (APC) and average replenishment cost (ARC) are expressed for each variant in Figure 2.

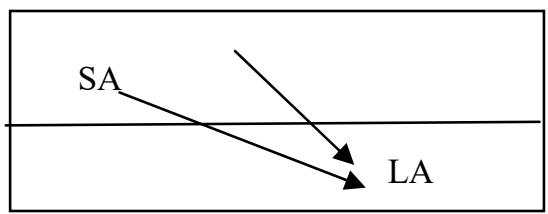

Variant 1: Picking from the single area (SA):

$\mathrm{APC}_{\mathrm{SA} F \mathrm{FLL}}>0$; average picking cost for full pallets

$\mathrm{APC}_{\mathrm{SA}} \mathrm{HU}_{-} \mathrm{CU}>0$; average picking cost for handling units and customer units

$\mathrm{ARC}=0$; average replenishment cost.

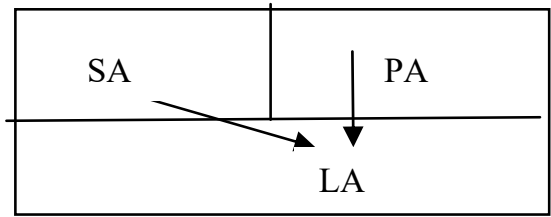

Variant 2: Picking from 2 separate zones: FPLL are picked from SA, but $\mathrm{HU}$ and $\mathrm{CU}$ are picked form PA; additional replenishment is required: $\mathrm{APC}_{\mathrm{SA} F \mathrm{FPL}}>0$; average picking cost for full pallets

$\mathrm{APC}_{\mathrm{PA} \mathrm{HU}_{\mathrm{CU}}}>0$; average picking cost for handling units and customer units $\mathrm{ARC}_{\mathrm{SA}_{-} \mathrm{PA}}>0$; average replenishment cost.

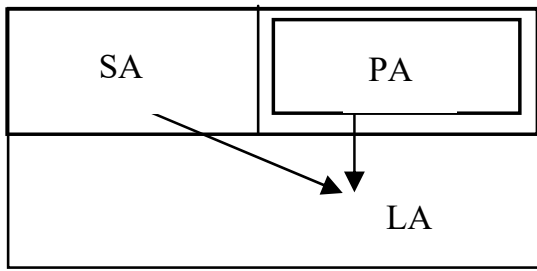

Variant 3: Picking from 2 separate zones, but PA is allocated in SA: FPLL are picked from SA, but $\mathrm{HU}$ and $\mathrm{CU}$ are picked from PA; additional replenishment is required:

$\mathrm{APC}_{\mathrm{SA} F \mathrm{FPL}}>0$; average picking cost for full pallets

$\mathrm{APC}_{\mathrm{PA}_{-} \mathrm{HU}_{-} \mathrm{CU}}>0$; average picking cost for handling units and customer units

$\mathrm{ARC}_{\mathrm{SA} P \mathrm{PA}} \mathrm{z}>0$; average replenishment cost.

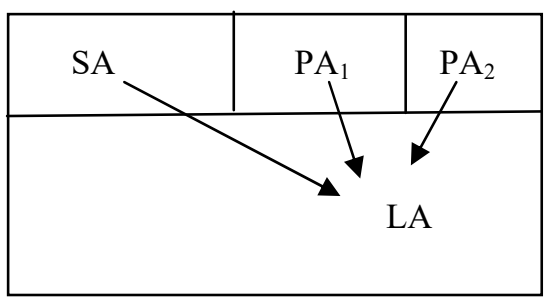

Variant 4: Picking from 3 separate zones: FPLL are picked from SA, but: $\mathrm{HU}$ from $\mathrm{PA}_{1}$, but $\mathrm{CU}$ accordingly are picked from $\mathrm{PA}_{2}$; additional replenishment is required for both picking areas: $\mathrm{APC}_{\mathrm{SA} F P L \mathrm{~L}}>0$; average picking cost for full pallets $\mathrm{APC}_{\mathrm{PA} 1} \mathrm{HU}_{\mathrm{H}}>0$; average picking cost for handling units $\mathrm{APC}_{\mathrm{PA} 2} \mathrm{CU}>0$; average picking cost for customer units $\mathrm{ARC}_{\mathrm{SA}_{\mathrm{PA} 1}}>0$; average replenishment cost from $\mathrm{SA}$ to $\mathrm{PA}_{1}$ $\mathrm{ARC}_{\mathrm{SA}} \mathrm{PA} 2_{2}>0$; average replenishment cost from $\mathrm{SA}$ to $\mathrm{PA}_{2}$ 
The key solution for choosing an appropriate variant is based on cheapest total handling cost (THC). The final - optimal variant can be evaluated by optimisation of THC, which is calculated for each single variant:

$\mathrm{THC}_{\mathrm{opt}}=\mathrm{MIN}\left(\mathrm{THC}_{1} ; \mathrm{THC}_{2} ; \mathrm{THC}_{3} ; \mathrm{THC}_{4}\right)$,

where: $\mathrm{THC}_{\mathrm{opt}}-$ Optimal Total Handling Cost;

$\mathrm{THC}_{1} ; \mathrm{THC}_{2} ; \mathrm{THC}_{3} ; \mathrm{THC}_{4}-$ Total Handling Cost for each variant accordingly.

The total handling cost of automated picking systems is not evaluated in this paper.

The total handling cost for variant 1 - Picking from the single area (SA) can be expressed:

$\mathrm{THC}_{1}=\sum_{\mathrm{i}=1}^{\mathrm{k}} \mathrm{Q}_{\mathrm{FPPL}} \mathrm{i} * \gamma_{\mathrm{i}} * \mathrm{APC}_{\mathrm{SA} \text { _FPLL }}+\sum_{\mathrm{i}=1}^{\mathrm{k}} \mathrm{Q}_{\mathrm{i}} *\left(1-\gamma_{\mathrm{i}}\right) * \mathrm{APC}_{\mathrm{SA} \mathrm{HU}_{-} \mathrm{CU}}$,

where: $\mathrm{Q}_{\mathrm{i}}$ - the total quantity of each SKU of picking orders (CU/month or CU/quarter);

$\mathrm{THC}_{1}$ - the total handling cost for variant 1 (EUR/month or EUR/quarter);

$\gamma_{i}$ - the coefficient of the part of the quantity picked in full pallets;

$Q_{F P L L_{-} i}-$ the quantity in full pallets picked of SA.

The quantity in full pallets picked of $\mathrm{SA}\left(Q_{F P L L_{-}}\right)$:

$\mathrm{Q}_{\mathrm{FPLL} \_\mathrm{i}}=\frac{\mathrm{Q}_{\mathrm{i}} * \gamma_{\mathrm{i}}}{\mathrm{A}_{\mathrm{FPLL}_{-} \mathrm{i}}}$

where: $A_{F P L L}-$-the quantity of full pallet of each SKU.

The total handling cost for variant 2 - Picking from 2 separate zones: from SA: FPLL are picked, but from PA: HU and CU are picked; additional replenishment is required:

$\mathrm{THC}_{2}=\sum_{\mathrm{i}=1}^{\mathrm{k}} \mathrm{Q}_{\mathrm{FPPL} \mathrm{i}} * \gamma_{\mathrm{i}} * \mathrm{APC}_{\mathrm{SA} A_{-} \mathrm{FPLL}}+\sum_{\mathrm{i}=1}^{\mathrm{k}} \mathrm{Q}_{\mathrm{i}} *\left(1-\gamma_{\mathrm{i}}\right) * \mathrm{APC}_{\mathrm{PA} \mathrm{HU}_{-} \mathrm{CU}}+\sum_{\mathrm{i}=1}^{\mathrm{k}} \mathrm{Q}_{\mathrm{FPPL} \mathrm{i}} *$
$\left(1-\gamma_{\mathrm{i}}\right) * \mathrm{ARC}_{\mathrm{SA} \mathrm{PA}_{\mathrm{P}} .}$

The total handling cost for variant 3 - Picking from 2 separate zones, but PA is located in SA: from SA: FPLL are picked, but from PA: HU and CU are picked; additional replenishment is required:

$\mathrm{THC}_{3}=\sum_{\mathrm{i}=1}^{\mathrm{k}} \mathrm{Q}_{\mathrm{FPPL} \_\mathrm{i}} * \gamma_{\mathrm{i}} * \mathrm{APC}_{\mathrm{SA}_{-} \mathrm{FPLL}}+\sum_{\mathrm{i}=1}^{\mathrm{k}} \mathrm{Q}_{\mathrm{i}} *\left(1-\gamma_{\mathrm{i}}\right) * \mathrm{APC}_{\mathrm{PA} \mathrm{HU}_{-} \mathrm{CU}}+\sum_{\mathrm{i}=1}^{\mathrm{k}} \mathrm{Q}_{\mathrm{FPPL}} \mathrm{i} *$ $\left(1-\gamma_{\mathrm{i}}\right) * \mathrm{ARC}_{\mathrm{PA}{ }_{-} \mathrm{SA}} \mathrm{Z}$.

The total handling cost for variant 3 - Picking from 3 separate zones: from SA: FPLL are picked, but from $\mathrm{PA}_{1}$ : $\mathrm{HU}$, but from $\mathrm{PA}_{2}$ : $\mathrm{CU}$ accordingly are picked; additional replenishment is required for both picking areas:

$$
\begin{aligned}
& T H C_{4}=\sum_{i=1}^{k} Q_{F P P L_{-} i} * \gamma_{i} * A P C_{S A_{-} F P L L}+\sum_{i=1}^{k} Q_{i} *\left(1-\gamma_{i}\right) * \alpha_{i} * A P C_{P A 1_{-} H U}+\sum_{i=1}^{k} Q_{i} * \\
& \left(1-\gamma_{i}\right) *\left(1-\alpha_{i}\right) * A P C_{P A 2_{-} C U}+\sum_{i=1}^{k} Q_{F P P L_{-} i} *\left(1-\gamma_{i}\right) * \alpha_{i} * A R C_{S A_{-} P A 1}+\sum_{i=1}^{k} Q_{F P P L_{-} i} * \\
& \left(1-\gamma_{i}\right) *\left(1-\alpha_{i}\right) * A R C_{S A_{-} P A 2},
\end{aligned}
$$

where: $\alpha$ - part of picking of HU (also part of replenishment from SA to PA1).

The additional decision refers to the choice of layout of picking addresses for each SKU corresponding to the picking route (Apsalons and Gromov, 2015). The methodology of evaluation of total picking cost consists of 5 main steps (Fig. 3):

1) Choosing (an optimal) variant of SA and PA layout.

2) Giving the description of total picking cost considering the layout of SKU in PA.

3) Obtaining of affecting factors (criteria) which, in their turn, change the total picking costs for variants of layout of SKU in PA.

4) Calculation of total picking cost for variants of layout of SKU in PA.

5) Accepting the decision of optimal variant of layout of SA and PA, and optimal variants of layout of SKU in PA.

The main restrictions of the methodology are the following. There is one row rack storing system available in the definite warehouse. Each item is placed on a separate pallet. To assume it to be a physical picking system: walk and pick (Tompkins et al., 2010). For this purpose, PA is established in this warehouse. The picking process will be carried out by picking HU and CU. Therefore, the ground and first levels of pallet racks are used as PA. The picking location of each item consists of two pallets: 1 pallet on the ground level and the other on the first level of the rack. 
For the 3rd variant of organizing the picking process of orders in the warehouse, picking has been carried out from two separate zones: SA and PA, but PA is located in SA, using PDO additionally, FPLL are collected from SA (second and higher levels of pallet racks are used), but HU and CU from PA (the first two levels of pallet racks are used).

We can explore the total handling cost for variant 2, for variant 3 and for variant 4 further we can explore by comparing two approaches of the layout of SKU in PA:

1) Single picking location for each single item - the replenishment is done in the picking process.

2) Various picking locations for each single item - the replenishment is done only just before the picking process or after it.

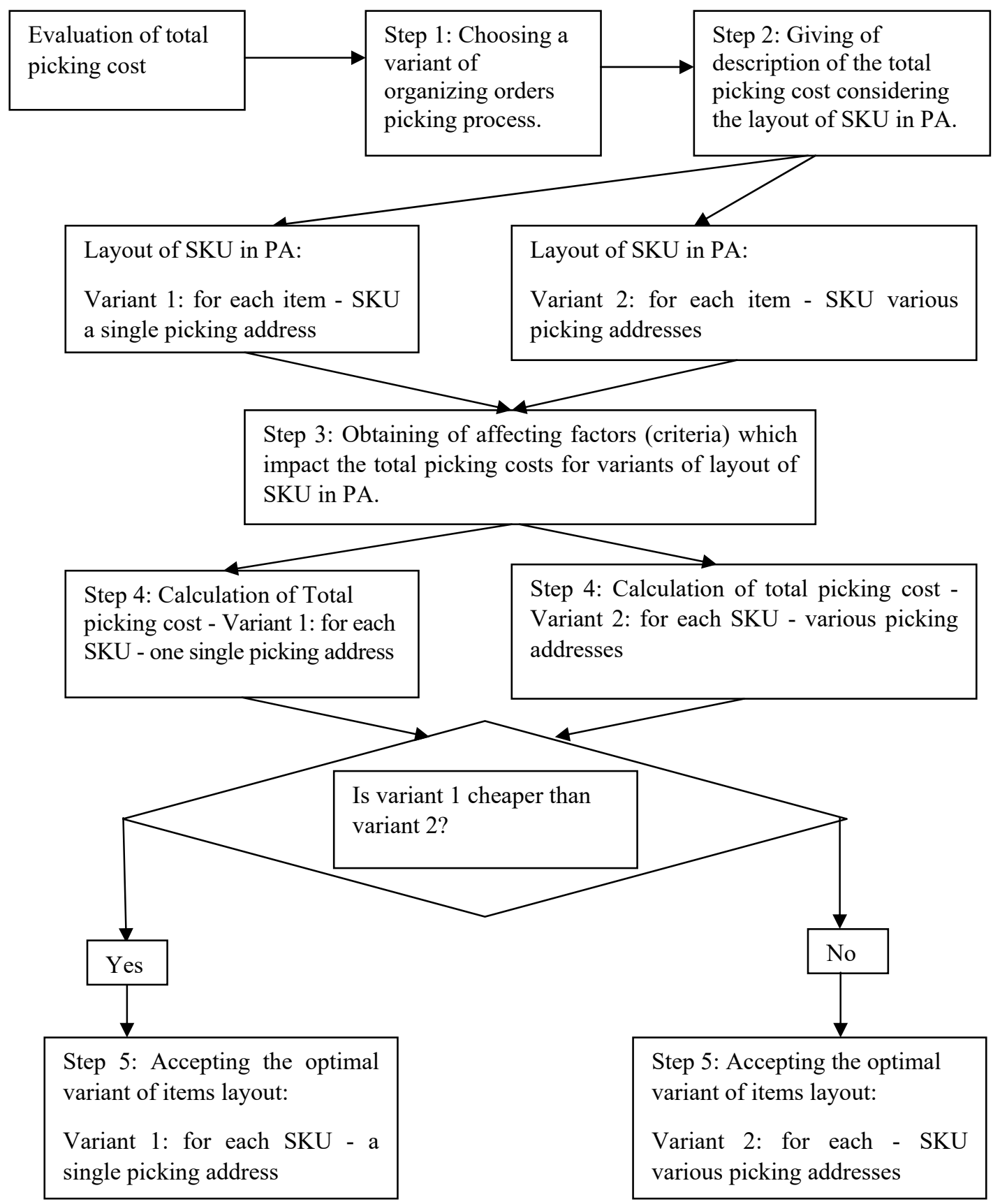

Figure 3. The evaluation methodology of total picking cost depends on different variants of SA and PA layout, and different variants of SKU layout in PA (developed by the authors) 
The first approach proceeds from the fact that the replenishment of a definite address is provided once the stock of definite SKU is below the critical level (Apsalons, 2012), and a specific inventory stock control method for procurement of goods is used in order to calculate this critical level. For this purpose re-order point (ROP) has been planned. It depends on the safety stock calculation, considering elimination of the stock - out (Lukinskiy V. and Lukinskiy Vl., 2016). For example, the Min/Max stock controlling method can be adjusted for this purpose. It means that the replenishment has being realized in uninterrupted picking process. An average replenishment cost could be higher than for the next approach.

The second approach excludes any replenishment in the picking time. If it is not allowed then quantity (stock) of each SKU in an uninterrupted picking process has to be sufficient from the beginning of the picking process till the end of it. When the process is performed automatically, it is obvious that it demands various picking addresses for each item, especially, if the quantities to be picked exceed two full pallets. Therefore, the replenishment is carried out outside of a picking process: the replenishment of picking addresses has to be performed before the picking process has started. (Table 1)

In order to compare the above mentioned approaches, a comparative table has been designed

Table 1. Characteristics of variants of the layout of SKU in PA as a hypothesis

\begin{tabular}{|c|c|c|}
\hline Characteristics & $\begin{array}{l}\text { Variant 1: for each SKU one single picking } \\
\text { address }\end{array}$ & $\begin{array}{l}\text { Variant 2: for each SKU various picking } \\
\text { addresses }\end{array}$ \\
\hline Replenishment & $\begin{array}{l}\text { Replenishment has to be done in an } \\
\text { uninterrupted picking process }\end{array}$ & $\begin{array}{l}\text { Replenishment has to be done outside of the } \\
\text { uninterrupted picking process }\end{array}$ \\
\hline $\begin{array}{l}\text { Number of picking } \\
\text { addresses for each SKU }\end{array}$ & The one single address for each single SKU & Various picking addresses for each single SKU \\
\hline $\begin{array}{l}\text { Comparable picking cost } \\
\text { from SA }\end{array}$ & Equal & \\
\hline $\begin{array}{l}\text { Comparable picking cost } \\
\text { from PA }\end{array}$ & $\begin{array}{l}\text { Probably cheaper than variant } 2 \text { due to shorter } \\
\text { travel distance in a picking route }\end{array}$ & $\begin{array}{l}\text { Probably more expensive than variant } 1 \text { due to } \\
\text { longer travel distance in a picking route }\end{array}$ \\
\hline $\begin{array}{l}\text { Comparable } \\
\text { replenishment cost from } \\
\text { PA to SA }\end{array}$ & $\begin{array}{l}\text { Probably more expensive than variant } 2 \\
\text { because if picking in some address and the } \\
\text { replenishment of this address are carried out at } \\
\text { the same time, then the picking process has a } \\
\text { priority to be carried out first but - the } \\
\text { replenishment after that }\end{array}$ & $\begin{array}{l}\text { Probably cheaper than variant } 1 \text { because picking } \\
\text { in some address and the replenishment of this } \\
\text { address are carried out at different time and } \\
\text { intervals, etc.: the replenishment is performed } \\
\text { before the picking process }\end{array}$ \\
\hline Picking route & \multicolumn{2}{|c|}{$\begin{array}{l}\text { Corresponds to the sequence which is determined by criteria for correct allocation of different SKU } \\
\text { (Apsalons and Gromov, 2015) }\end{array}$} \\
\hline Picking technology & \multicolumn{2}{|l|}{ Pick and walk, not automated } \\
\hline $\begin{array}{l}\text { Picking equipment to be } \\
\text { used }\end{array}$ & \multicolumn{2}{|c|}{$\begin{array}{l}1 \text { row pallet racks for design of SA and PA, for picking from SA - high level pallet forklifts, but for } \\
\text { PA - electric pickers }\end{array}$} \\
\hline $\begin{array}{l}\text { Number of orders picked } \\
\text { at once in one single } \\
\text { route }\end{array}$ & \multicolumn{2}{|c|}{$\begin{array}{l}\text { If volume of picking different SKU per one order is almost equal to the capacity of picking } \\
\text { technique: one order - one picker. } \\
\text { If the volume of picking different SKU per one order is higher than the capacity of picking } \\
\text { technique: one order - M number of pickers. } \\
\text { If the volume of picking different SKU per one order is less than the capacity of picking technique: } \\
\text { combined picking of several orders in a group is used: N number of orders - one picker. }\end{array}$} \\
\hline
\end{tabular}

\section{Practical Example of Total Handling Cost Calculation for Logistics Centre $\mathbf{Y}$}

"Y" is a renowned logistics centre in the Baltic States. The profit or losses account of logistics centre "Y" has been imported from the "Lursoft" data bases of enterprises (2017). By a special order, the authors have developed a warehouse dashboard of division of enterprise's total costs broken down by processes and by accounting groups (Table 2).

The 3rd layout of organizing a picking process has been used in this company for many years. The management of the logistics centre is sure that this variant of layout is suitable for the company, and might be the cheapest. But, unfortunately, nobody knows whether the 3rd layout is the cheapest, indeed. In practice it is not sufficient just to get a profit or losses account.

In order to confirm that one of the layouts will be the cheapest by minimising total handling cost, the authors have developed the logistics audit. The first step is to obtain the warehouse scoreboard proposed by the authors in Table 2. TR means total revenue for one year, but $\mathrm{TC}_{\mathrm{log}}$, in its turn, presents the total logistical cost for one year. The main processes affecting the total picking cost are the 
replenishment of picking locations ( $4 \%$ from total cost), picking of full pallets ( $5 \%$ from total cost) and picking of both handling units and customer units (31\% from total cost). The labour cost is up to $14 \%$, the rent takes $-25 \%$ of the total cost. It has been calculated that the mechanic handling system (MHS) demands $42 \%$ of the total cost, whereas WMS is equal to $16 \%$ of the total logistics cost. As total revenue corresponds to almost EUR 3 million a year, the total logistics cost amounts up to $80 \%$ of the total revenue.

At the end of Table 2 on activities base cost (abc) has been calculated. It shall be noted that the information has been collected on the basis of this warehouse operation.

Table 2. Division of total logistics cost by logistics processes and by accounting groups

\begin{tabular}{|c|c|c|c|c|c|c|}
\hline Total Revenue (TR) & 2995455 & EUR/year & & & & \\
\hline Total Logistics Cost $\left(\mathrm{TC}_{\log }\right)$ & 2417813 & EUR/year & $80.72 \%$ & $\mathrm{TC}_{\log }$ from $\mathrm{TR}$ & & \\
\hline Costs of processes & Labour & Rent & MHS & WMS & TC process & TC\% \\
\hline 1. Receiving goods & 32400 & 102964 & 71228 & 18234 & 224826 & $9.23 \%$ \\
\hline 2. Replenishment of picking locations & 45600 & 0 & 46222 & 9020 & 100843 & $4.14 \%$ \\
\hline 3. Storing & 40800 & 222124 & 275118 & 79193 & 617235 & $25.34 \%$ \\
\hline 4. Picking of full pallets & 20400 & 0 & 82515 & 21799 & 124714 & $5.12 \%$ \\
\hline 5. Picking of $\mathrm{HU}$ and $\mathrm{CU}$ & 88800 & 258123 & 335000 & 61756 & 743679 & $31.27 \%$ \\
\hline 6. Routing and delivery of orders & 12000 & 0 & 269000 & 87295 & 368295 & $15.12 \%$ \\
\hline 7. Receiving and processing of orders & 69600 & - & 0 & 71190 & 140790 & $5.78 \%$ \\
\hline 8. Returning of goods & 10800 & 5222 & 6000 & 35220 & 57242 & $2.35 \%$ \\
\hline 9. Customs clearance operations & 10008 & - & 0 & 2902 & 12910 & $0.53 \%$ \\
\hline 10. Other processes & 8412 & 10100 & 4125 & 4644 & 27281 & $1.12 \%$ \\
\hline TOTAL & 338820 & 598533 & 1089208 & 391252 & 2417813 & $100.00 \%$ \\
\hline$\%$ from total cost & $14.01 \%$ & $24.76 \%$ & $42.15 \%$ & $16.18 \%$ & $100.00 \%$ & \\
\hline$\%$ from sales & $11.31 \%$ & $19.98 \%$ & $36.36 \%$ & $13.06 \%$ & $80.72 \%$ & \\
\hline Cost per one order & 2.21 & 3.91 & 7.12 & 2.56 & 15.80 & \\
\hline Cost per $1 \mathrm{HU}$ & 0.08 & 0.14 & 0.26 & 0.09 & 0.57 & \\
\hline Cost per $1 \mathrm{OL}$ & 0.04 & 0.08 & 0.14 & 0.05 & 0.32 & \\
\hline Cost per $1 \mathrm{CU}$ & 0.02 & 0.03 & 0.05 & 0.02 & 0.11 & \\
\hline Cost per 1 square meter of area, $\mathrm{m} 2$ & 19.36 & 34.20 & 62.24 & 22.36 & 138.16 & \\
\hline Cost per $1 \mathrm{~kg}$ & 0.12 & 0.22 & 0.40 & 0.14 & 0.89 & \\
\hline Cost per $1 \mathrm{SKU}$ & 398.61 & 704.16 & 1281.42 & 460.30 & 2844.49 & \\
\hline
\end{tabular}

Table 3 shows the inbound data that served as indicators for calculation of the total handling cost of orders' picking layouts in the warehouse. All indicators refer to the existing 3rd variant of SA and PA layout. The authors would like to draw the attention to the fact that only the last one refers to obtaining the part $\alpha$-part of picking of HU (also part of replenishment from SA to PA1) and it will be used for calculation of 4 th variant of the layout.

Table 3 provides the total costs for picking from SA and PA, and these values correspond to the values in the warehouse scoreboard. By using the principle of division of orders i.e., full pallets are collected from SA, but HU and CU from PA (in the 3rd variant of layout). In order to simplify calculations one picking point means one visit to a definite picking address. Essential data then are the number of picked full pallets, the number of picked total HU from PA, the number of replenished full pallets from SA to PA, and the number of picking points (visits of pickers) in PA. Additionally, it is known that the average number of HU picked at one picking point (PP) is 3.25 handling units.

The second step is to calculate base cost $(\mathrm{abc})$ for the 3rd variant of the area layout, and then changing location-developed average cost for variants 1,2 and 4. The results of calculation are compiled in Table 4. 
Table 3. Inbound data as indicators for calculation of total handling cost of orders picking layouts

\begin{tabular}{|l|l|l|l|}
\hline Indicator & Designations & Value & Measurement \\
\hline Total picking cost of full pallets & TC picking_SA & 124714 & EUR/year \\
\hline Total picking cost of HU and CU & TC $_{\text {pickin__PA_H__U }}$ & 743679 & EUR/year \\
\hline Number of picked FPLL & N_FPLL & 36300 & FPLL/year \\
\hline Number of picked total HU from PA & N_HU_virtual & 4250000 & HU/year \\
\hline $\begin{array}{l}\text { Average number of HU picked on one picking } \\
\text { point (PP) }\end{array}$ & N_HU_PP & 3.2458 & HU/PP \\
\hline Total cost of replenishment from PA to SA & TC replenishment & 100843 & EUR/year \\
\hline $\begin{array}{l}\text { Number of replenished FPLL from SA to PA } \\
\text { Number of picking points in PA }\end{array}$ & N_Repl_Fpll & 239200 & FPLL/year \\
\hline $\begin{array}{l}\text { Part of picking of HU (also part of replenishment } \\
\text { from SA to PA1) }\end{array}$ & $\alpha$ & 1309384 & PP/year \\
\hline
\end{tabular}

Considering the 1st variant of the layout, one shall pay attention to the fact that PA exists in a warehouse, and that the average replenishment cost, in this case, is zero. After introducing PA, the average picking cost and average replenishment cost appear (variant 2;3 and 4). Thereto, in the 4th variant of the layout, double cost could be considered: i.e., the average picking cost from PA1 and PA2, and the average replenishment cost from SA to PA1, and from SA to PA2.

Table 4. Activities - based cost calculation results for each layout of areas

\begin{tabular}{|c|c|c|c|}
\hline Variant 1 & Designations & Value_abc & Measurement \\
\hline Average picking cost of full pallets & APC_SA_FPLL & 0.43564 & EUR/FPLL \\
\hline $\begin{array}{l}\text { Average picking cost of handling units and customer units per picking } \\
\text { point from SA }\end{array}$ & APC_SA_HU_CU & 0.85194 & EUR/PP \\
\hline Average replenishment cost & ARC_SA_PA & 0 & EUR/PP \\
\hline Variant 2 & Designations & Value_abc & Measurement \\
\hline Average picking cost of full pallets & APC_SA_FPLL & 3.43564 & EUR/FPLL \\
\hline $\begin{array}{l}\text { Average picking cost of handling units and customer units per picking } \\
\text { point from PA }\end{array}$ & APC_PA_HU_CU & 0.56796 & EUR/PP \\
\hline Average replenishment cost from SA to PA & ARC_SA_PA & 0.48482 & EUR/FPLL \\
\hline Variant 3 & Designations & Value_abc & Measurement \\
\hline Average picking cost of full pallets & APC_SA_FPLL & 3.43564 & EUR/FPLL \\
\hline $\begin{array}{l}\text { Average picking cost of handling units and customer units per picking } \\
\text { point from PA }\end{array}$ & APC_PA_HU_CU & 0.56796 & EUR/PP \\
\hline Average replenishment cost from SA to PA (in the same zone) & ARC_SA_PA_Z & 0.42158 & EUR/FPLL \\
\hline Variant 4 & Designations & Value_abc & Measurement \\
\hline Average picking cost of full pallets & APC_SA_FPLL & 3.43564 & EUR/FPLL \\
\hline $\begin{array}{l}\text { Average picking cost of handling units per picking point from picking } \\
\text { area } 1\end{array}$ & APC_PA1_HU & 0.56796 & $\mathrm{EUR} / \mathrm{PP}$ \\
\hline $\begin{array}{l}\text { Average picking cost of handling units per picking point from picking } \\
\text { area } 2\end{array}$ & APC_PA2_CU & 0.43122 & EUR/PP \\
\hline Average replenishment cost from SA to PA1 & ARC_SA_PA1 & 0.48482 & EUR/FPLL \\
\hline Average replenishment cost from SA to PA2 & ARC_SA_PA2 & 0.92116 & EUR/FPLL \\
\hline
\end{tabular}

The third step concerns the calculation of THC that was done by the authors by using formulas from (20) to (24) (Fig. 4). As a result of the calculation, the authors have come to the conclusion that the 4 th variant appears to be more effective. And that means that the administration of the logistics centre has made a mistake in their assessment, because after the calculation the 4th variant has proved to be the cheapest one. The second cheapest is the 3rd variant of the layout. The difference between the 4 th and the 3rd variant is $15000 \mathrm{EUR} /$ year. From the authors' point of view it is important to keep focus on the part $\alpha$ - of HU picking (and also on the part of replenishment from SA to PA1) which constitutes $60 \%$. By 
enhancing part $\alpha$ till $80 \%$, the 3rd variant of the layout will become the cheapest. An accurate calculation of activities, based their cost is equally important, as it depends on labour costs, MHS cost, WMS cost and the rent.

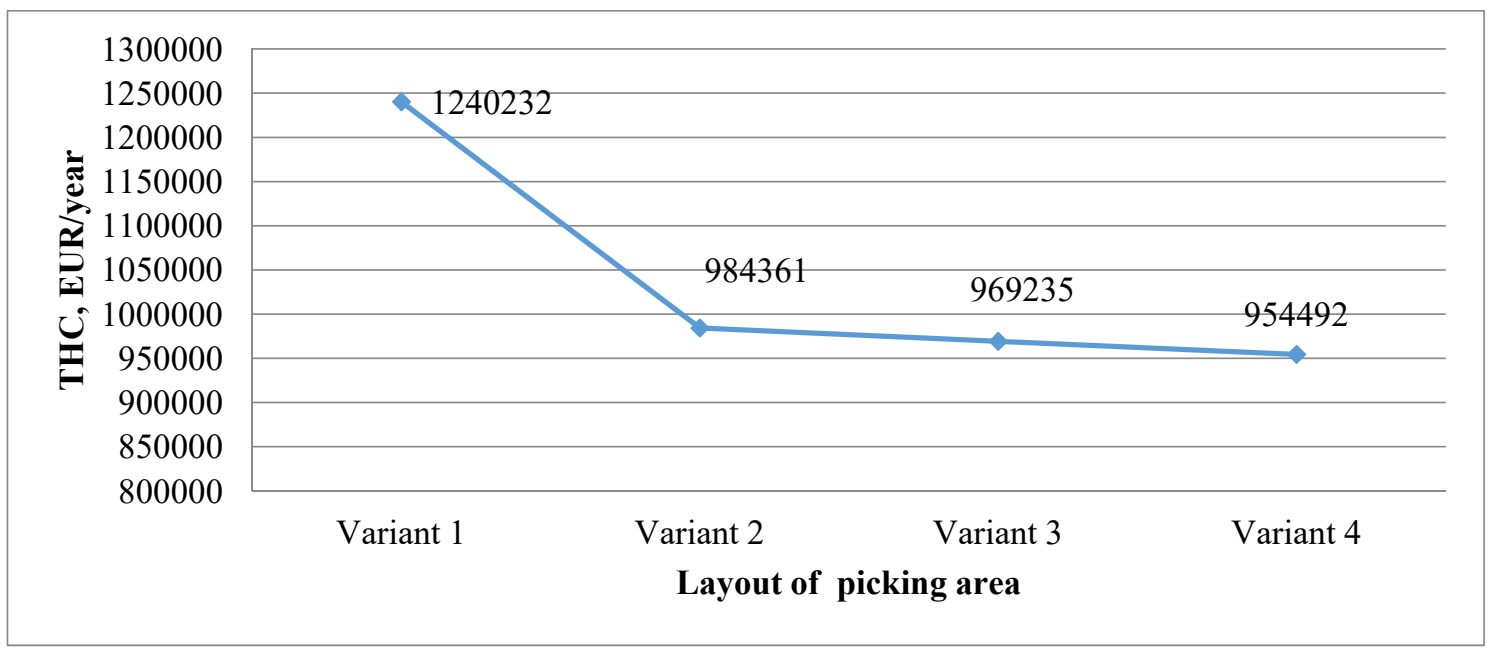

Figure 4. Results of calculated THC for each variant of PA layout for company Y for the next year

Seasonal changes can also affect the results of each quarter. Different layouts of PA can be appropriated, to the extent possible for each season and quarter. Furthermore, it is highly possible to adjust the mixture of layout variants. For the fulfilment of this task, all active warehouse data would be necessary. Consequently, there is no single answer to the question which variant of PA layout will be the cheapest each time. It depends on each individual warehouse parameters and data. Therefore, this kind of evaluation must be carried out separately for each individual warehouse.

\section{Conclusions}

The main task of the paper is to develop the methodology of evaluation of picking cost within an uninterrupted picking process, and not to prove it by practical data or experiments, which will be the focus of further researches.

The authors of the paper have proposed and analysed several variants of organizing the picking process of orders in the warehouse. The key solution for choosing an appropriate variant is based on the cheapest THC. The final optimal variant can be evaluated through optimisation of THC, which is calculated for each single variant separately. In order to do this, the average picking costs and average replenishment cost have to be calculated for each picking variant separately. There are lot of various constraints, which are different in each warehouse:

1) Number of SKU in the warehouse to participate in orders picking process and allocated in SA and PA;

2) Inventory turnover expressed in days for each SKU;

3) Size (length, depth and height) for each SKU handling and customer units;

4) Seasonal fluctuations of ordered quantities of each SKU;

5) Type of bays (racks) in SA and PA;

6) Some SKU have terms of validity;

7) Some SKU have to be kept in separate areas (zones), etc.

It confirms the statement that the conditions of zoning for each separate warehouse have to be verified by practical data. Therefore, for each single situation experts can obtain different results in order to choose appropriate variants of organizing the orders picking process in a warehouse.

The total handling cost for variant 2, for variant 3 and for variant 4 can be explored by comparing two approaches of the layout of SKU in PA. Characteristics of variants of approaches to the layout of SKU in PA are given by the authors as a hypothesis, though the authors understand that these two approaches also need to be verified by using practical data.

The warehouse clerk or the planning specialist has to be aware that at different time periods the demand for any item also changes. Therefore, it is necessary to make recalculations of parameters of PA 
and evaluation of the total handling cost for the purpose in view to minimise this cost, and to make the SKU allocation optimal. Besides that, we shall take into consideration the fact that the popularity of SKU has a tendency to change in the periods that follow. For minimising the costs, including in picking process, it is important to change the parameters and the conditions of PA picking process so that they correspond to the needs of the next time period. A certain number of orders or definite calendar time period may serve as a criterion to signal a start for the recalculation, for example, seasonal changes. In that case, the inbound data for the recalculation of PA parameters is the data of the previous orders and orders received as a result of procurement. When procured orders are fulfilled, a new group of data is created once again: so, further on, we are having both the previous orders and the procured ones.

The examples described in the paper might be useful for WMS on condition that the existing algorithms are improved, and, after that, programmed and exported in this WMS.

\section{References}

1. Andriansyah, R., Etman, P. and Rooda, J. (2009) Simulation model of a single - server order picking workstation using aggregate process times. In: Advances in System Simulation, 2009, SIMUL '09. First International Conference, Porto, pp. $23-31$.

2. Apsalons, R. (2012) The management of logistics centres. Riga: Burtene (in Latvian).

3. Apsalons, R. and Gromov, G. (2015) Using of logistics' principles for picking items in railway warehouses. In: Development of infrastructure and logistics technologies of transport systems. International scientific - practical conference September 23 - 25, 2015. Sankt - Petersburg: FGBOU VO PGUPS (in Russian), pp. 93 - 100.

4. Ballou, R.H. (1999) Business Logistics Management. $4^{\text {th }}$ edition. USA: Prentice - Hall Inc.

5. Bustillo, M., Menendez, B., Pardo, E.G. and Duarte, A. (2015) An algorithm for batching, sequencing and picking operations in a warehouse. In: Industrial Engineering and Systems Management (IESM), 2015 International Conference on, Seville, pp. 842 - 849.

6. Frazelle, E.H. (2002) World-Class Warehousing and Material Handling. India: McGraw-Hill Education Pvt. Limited.

7. Koffler, M., Beham, A., Wagner, S. and Affenzeller, M. (2014) Affinity based slotting in warehouses with dynamic order patterns. - www.springerlink.com (2017.06.02)

8. Koster, D. (1999) Efficient order batching methods in warehouses. Intelligent Journal of Production, Res., Vol. 37, No. 7, pp. 1479-1504.

9. Lukinskiy, V. and Lukinskiy, V1. (2016) Evaluation of the influence of logistic operations reliability on the total costs of supply chain. In: Transport and Telecommunication, November 23, 2016, volume 17, No. 4, pp. $307-313$.

10. Lukinskiy, V.S., Lukinskiy, V.V. and Pletneva, N.G. (2016) Logistics and management of supply chains. Moscow: Jurite (in Russian).

11. "Lursoft" data bases of enterprises. "Lursoft IT" Ltd. - www.lursoft.lv (2017.06.10)

12. Mantel, R., Schuur, P. and Heragu, S. (2007) Order oriented slotting: a new assignment strategy for warehouses, Eur. J., Ind. Eng. 1(3), pp. 301-316

13. Solovyova, T. (2008) Organising commissioning of wholesales. Technologies of warehouses (in Russian), 1/2008, pp. $16-23$.

14. Tompkins, J.A., White, J.A., Bozer, Y.A., and Tanchoco, J.M.A. (2010) Facilities planning. 4th edition. UK: John Wiley\&Sons, Ltd.

15. Won, J. and Olafson, S. (2005) Joint order batching and order picking in warehouse operations. International Journal of Production Research, 4/1/2005, pp. 1427 - 1442.

16. Yuryev, E. (2008) Dynamic Slotting. Nowadays warehouse. Journal of warehousing logistics (in Russian), 3/2008, pp. 34-41. 